\title{
DOMESTICATED MOSQUITOES
}

\section{Colonization and the growth of mosquito habitats in North America}

\author{
Urmi Engineer Willoughby
}

Humans never wanted to cultivate habitats that encouraged mosquito breeding and habitation. However, human settlements and agricultural landscapes often created conditions that attracted mosquitoes, and humans themselves provided a crucial source of blood that enabled the survival and fecundity of several mosquito species. In North America, mosquito populations grew in the context of European colonization and African slavery. Prior to 1500, indigenous mosquitoes lived alongside Native American agricultural communities, as they did in Afro-Eurasia. By the sixteenth century, ecological changes resulting from the Columbian Exchange brought new species of mosquitoes to the Americas. Human migrations and environmental alterations caused by colonization also enabled the expansion of regional, indigenous mosquito populations such as Anopheles, which proliferated in the seventeenth through nineteenth centuries. At the same time, ongoing transatlantic commerce, migrations, and urban ports facilitated the growth and dominance of a newly imported species, Aedes aegypti (Ae. aegypti).

It is possible to discern historical patterns of the emergence and growth of mosquito habitats from accounts of contemporary observers, medical and epidemiological records, and present-day research on mosquito-borne diseases. Historical accounts such as travel journals, diaries and medical literature often include observations of local flora and fauna, including insect life. These provide insights on the presence of mosquitoes, as well as the relative increase or decrease in their abundance. Historical records that indicate the presence of yellow fever and malaria is especially helpful in determining the presence of an established population of a particular species capable of carrying the requisite viruses and parasites: accounts of the earliest recorded epidemics of yellow fever demonstrate the presence of Ae. aegypti, while descriptions of intermittent and miasmatic fevers indicate the presence of various Anopheles species. Present-day studies of 
vector mosquitoes show the global spread of certain Aedes species (Ae. aegypti and Ae. albopictus), and regional dominance of dozens of Anopheles species throughout the world. Given the rise of mosquito populations stemming from humanity's propensity to transport these insects and encourage their growth, are humans responsible for the prolific rise of anthropophilic (human-loving) mosquito populations? Since humans accidently enabled the growth of mosquitoes, are they justified in their efforts to control these mosquitoes and even seek to eradicate them? And is it even possible for humans to eradicate a species that has adapted and evolved to live alongside humans?

\section{Settlement}

Mosquito populations grew alongside human settlements in native America. Various indigenous species of Anopheles mosquitoes lived in the diverse forest, wetland and grassland environments of eastern North America, including $A n$. quadrimaculatus, An. albimanus, An. pseudopunctipennis and others (Kiszewksi et al. 2004, 488; Webb 2009, 67). In western North America, native Anopheles species included An. pseudopunctipennis, An. freeborni, perhaps An. crucians (Sinka et al. 2010, 8-9; Mullen et al. 2002, 243). Native North American experiences indicate a familiarity with mosquitoes. It is likely that native agricultural practices, for example, such as the construction of chinampas and maize fields, attracted mosquitoes. For centuries, Indigenous farmers in Mexico built chinampas, or islands of raised fields within lakes and lowlands. Anopheles mosquitoes readily bred in these maize fields, as well as on lake shores, in canals and in swamps surrounding Tenochtitlán and other cities in the Valley of Mexico and the Yucatán. Deforestation and the construction of maize fields throughout the Mississippi Valley likely created mosquito habitats in this lowland valley. It follows that mosquito populations likely decreased with the decline of Mississippian Cahokia and Moundville urban centres in the fourteenth and fifteenth centuries.

The habits of Anopheles mosquitoes vary greatly according to species. Some species rarely live near human settlements, while others commonly occupy areas close to human dwellings. Several species' attraction to human settlements appears to arise from their desire to feed on human blood and breed in humanbuilt environments. In the Caribbean and Central America, it is likely that $A n$. albimanus populations lived near Indigenous settlements. In mainland North America, several species, including An. albimanus, An. pseudopunctipennis, An. freeborni, An. quadrimaculatus and An. walkeri, may have adapted to living near Indigenous agricultural settlements in the Valley of Mexico, the Great Lakes region and the Mississippi Valley.

European colonization in the Caribbean and Mexico created additional habitats that attracted An. albimanus. Entomological studies demonstrate that this species has developed a strong preference for feeding on human blood and breeding in humanized environments, such as in cleared fields near human settlements, rather than in forested areas away from human communities. It would seem 
that the construction of roads and use of domesticated animals for transport also contributed to the growth of mosquitoes. Entomologists have shown that $A n$. albimanus can breed in very small pools of water, such as in borrow pits, wheel ruts and hoof prints (Sinka et al. 2010, 10).

In mainland North America, European exploration and early contacts with Indigenous peoples and environments also indicate the presence of native mosquitoes. Historical evidence indicates that malaria parasites arrived in North America with the earliest European colonists in the sixteenth and seventeenth centuries. Malaria had been endemic in parts of Europe during this period, especially in coastal regions of Italy, Iberia and England, which emerged as maritime centres. Malaria parasites then found new hosts in native Anopheles species in the Americas. Even if there is not much evidence for malaria during the early contact period, it is possible that malaria was at the root of cycles of fever and hunger that caused high mortality and that afflicted newly established colonial settlements and exploratory missions. Moreover, malaria appears to have been part of the cycle of disease and famine that devastated the English settlement at Jamestown in 1607 (Hirsch 1883, 229; Singer 1962, 455-456; Webb 2009, 74). In 1718-1720, the first French expeditions in the Mississippi Delta endured a severe cycle of fever and hunger that are consistent with symptoms of malaria (Usner 1992, 34-36). However, there is not much evidence that malaria was a significant presence or problem in North America until the mid-seventeenth century, when outbreaks appeared more frequently in New England after about 1650. It is possible that malaria played a role in disease epidemics that afflicted Native American populations in the southeast in the sixteenth through eighteenth centuries. However, as Paul Kelton and others have argued, the highest rates of depopulation occurred during the Great Southeastern Smallpox Epidemic that began in 1696, and slave raids exacerbated population loss and disease vulnerability in the region (Kelton 2007, 189-191; Usner 1992, 18-24).

Indeed, Anopheles mosquitoes in the Mississippi delta lived alongside a diversity of insects and other species in the wetland environment. French missionary accounts that describe the earliest European experiences in the region demonstrate the presence of large numbers of mosquitoes drawn to the blood of humans who ventured into the swamps. In 1727, the French missionary Father Du Poisson travelled up the Mississippi River from New Orleans to the Arkansas post, and described in great detail his encounters with insects, including mosquitoesor maringouins in vernacular French. Beginning his journey in May, which he described as "the season of the greatest heat, which is increasing every day," he also complained about the lack of food. However,

the greatest torture-without which everything else would have been only a recreation, but which passes all belief, and could never be imagined in France unless it had been experienced-is the mosquitoes, the cruel persecution of the mosquitoes. ... This little creature has caused more 
swearing since the French came to Mississippi, than has been done before that time in all the rest of the world.

(Thwaites 1900, 289)

Du Poisson goes on to describe the "millions of mosquitoes" that attacked him and his companions in the morning, afternoon and throughout the night.

As newcomers built new settlements in close proximity to mosquito habitats, settlers provided an abundant food source for mosquito populations. Early colonial settlements may have disrupted some mosquito habitats but they created many new ones. Settlement activities included land clearance, water management, shelter construction and crop cultivation. In many cases, the clearing of land caused deforestation and resulted in the decline of numerous animal species, particularly those that lived in the forest canopy, including rodents, bats and birds that fed on mosquitoes (Moore 2000, 421; McNeill 2010, 48; Watts 1987, 39). At the same time, drainage canals created new freshwater ponds, which provided additional breeding spaces. Accounts of European and Euro-American colonial settlements in North America often described outbreaks of fever, which fit the description of malaria. By the end of the colonial period, malaria was endemic in pockets throughout the eastern Atlantic and Gulf coasts, indicating the presence of Anopheles.

Ongoing European and American settlement in the eighteenth and nineteenth centuries helped establish large populations of An. quadrimaculatus across eastern North America, which grew in tandem with the establishment of agricultural settlements in the Ohio and Mississippi Valleys. Such presence of An. quadrimaculatus became established in rural areas throughout eastern North America, as is indicated by ongoing outbreaks of malaria among early colonists during the territorial expansion of the United States in the early nineteenth century (Nash 2006, 23; Humphreys 2001; Ackerknecht 1945; Chapin 1884). In the 1920s, entomologists found that in the Mississippi Delta region, An. quadrimaculatus "greatly predominates over all other species" (Barber et al. 1927, 2494), owing in part to the observation that both An. quadrimaculatus and An. walkeri populations grew near human dwellings. Both species continue to show a preference for feeding on humans and living in built environments. Entomologists reveal that An. walkeri adults "enter dwellings at night to feed on humans and then retire to secretive daytime hiding places" (Carpenter et al. 1955, 55). Similarly, An. quadrimaculatus are mainly night-time feeders, and then rest during daylight hours "in dark corners in buildings, underneath houses, in stables, in hollow trees, and other shelters" (Carpenter et al. 1955, 52). An. Quadrimaculatus also prefers large natural and artificial bodies of water, including lagoons, lakes, marshes, rice fields and irrigation channels (Sinka et al. 2010, 8-11). It seems that, over the last 500 years in North America, the single most important event to favour multiplication and growth of two key mosquito species was the arrival and expansion of Old World settlers. 


\section{Plantation agriculture}

The rise of African slavery and plantation agriculture in the Atlantic Americas transformed mosquito-human relationships. The combination of the Atlantic slave trade and plantation agriculture in the Caribbean, Atlantic and Gulf Coast regions led to the growth of North American mosquito populations, including native Anopheles species and new Aedes species from Afro-Eurasia.

Such human-caused environmental transformations allowed Ae. aegypti mosquitoes to become a globally dominant species that lived alongside humans in maritime and urban environments in the seventeenth through nineteenth centuries. Entomologists today consider Ae. aegypti to be a "domesticated" species because of its proclivity to inhabit human settlements and thrive in humanbuilt environments. In the wild, Ae. aegypti live and breed in forests, laying eggs in tree holes and other cavities. But when exposed to human environments, they typically breed in artificial water containers made of various materials including clay, wood, cement and, more recently, plastic, in close proximity to human residences (Carpenter et al., 1955, 262). Aedes originated in sub-Saharan Africa, and spread throughout the globe with European colonial projects in the seventeenth through nineteenth centuries. Although it is unknown exactly when Ae. aegypti became an anthropophilic species, it is possible that living alongside early agricultural communities in tropical West Africa, or being transported to the Americas after 1500, accelerated this process. Later, after arriving in the Americas, Ae. aegypti travelled across the Pacific on ships and boats to become established in urban environments of coastal Asia and Australia by the close of the nineteenth century (Powell and Tabachnick 2013, 12-13).

The notion of "domesticated" mosquitoes offers an ironic understanding of their evolutionary relationship with humans. Historically, humans have unintentionally supported the growth of numerous animals and plants, usually considered to be pests or weeds, such as lice, rats, cats and jackals, and in some places even bears. The increase of mosquito numbers in humanized environments demonstrates the evolutionary success of mosquitoes, as well as their tenacious ability to resist human efforts to control or eradicate them. Anthropophily benefited mosquitoes that survived by being able to consume human blood meals, even if such mosquitoes did not provide any known benefit to human communities. Due to the role of certain mosquito species as vectors of disease, their attraction to people has caused devastating diseases and mortality to human populations.

Popular sources have depicted mosquitoes as humanity's most dangerous threat, including Bill Gates who has called them "the deadliest animal in the world" (Gates 2016). From the perspective of Ae. aegypti, it has increased its temporal and spatial reach by adapting to human environments. One of the key ways in which Ae. aegypti modified its behaviour was by developing a preference for blood of humans over non-human primates. Sedentary human communities provided an abundant and stable source of blood-as opposed to 
feeding on migratory birds or ungulates-so that Ae. aegypti's adaptation to humans allowed it to grow beyond its former geographical reach (Powell and Tabachnick 2013, 11).

Ae. aegypti has been remarkably successful in colonizing the Americas. This mosquito grew on plantations and throughout the infrastructure that supported transatlantic capitalist networks, including densely populated port cities and ships. Because Ae. aegypti served as the main vector of the yellow fever virus, it is possible to trace the presence of the species by studying epidemic patterns. Yellow fever incidence in the Atlantic World can therefore reveal links between transatlantic commerce, plantation agriculture, urbanization and the growth of $A e$. aegypti populations. Such events suggest that Ae. aegypti arrived in the Americas in the centuries of accelerated Atlantic trade between 1600 and 1800, with the earliest known outbreak of yellow fever occurring in the 1640s in Barbados, followed by various epidemics in the Caribbean that indicated this mosquito's presence on Atlantic ships and in port cities. By the 1700s, seasonal waves of Ae. aegypti were entering South Carolina and the Chesapeake, extending as far north as Quebec (Patterson 1992, 857; Augustin 1909, 652).

That sugar plantations in the Caribbean, Brazil and Louisiana attracted Ae. aegypti populations is evidenced by large-scale epidemics during the early phases of establishing plantations and port cities. The earliest known outbreaks of yellow fever were in sugar colonies in Barbados, as well as in Guadeloupe, St. Kitts and Cuba. Descriptions of Caribbean plantations show the ubiquity of mosquitoes and other insects. In Jamaica in 1688, Hans Sloane described how enslaved residents of sugar plantations lit fires to repel "gnats, mosquitoes, and flies." James Goodyear and others explain that sugar cultivation and production served to facilitate the growth of Ae. aegypti mosquitoes in several ways. There was clearance of land for sugar fields, which increased deforestation with the demand for wood to fuel sugar mills. To create additional plantations in lowland regions, there was clearance of marshes, swamps and bogs. Drainage canals and ditches also raised susceptibility to flooding, and created new freshwater habitats for mosquitoes. For example, on Louisiana plantations in the nineteenth century, drainage ditches and canals were excavated to keep sugar crops from flooding. French authorities had granted land tracts for plantations that formed 90-degree angles to the river, so that each had river access with a back swamp for drainage, creating additional freshwater ponds and ditches for mosquitoes to lay eggs (Willoughby 2017; Hilliard 1979, 258-263). The plantations also fostered growth of $A$ e. aegypti mosquitoes by creating breeding places in clean water collected in cisterns, water-barrels and clay pots (McNeill 2010, 205; Goodyear 1978, 13).

In addition to fostering Ae. aegypti populations, plantation environments likewise enabled the growth of Anopheles populations. The drainage ditches, canals and irrigated fields served to create many breeding spaces for this other mosquito species too. In the Caribbean, deforestation and soil erosion in lowland environments created new freshwater swamps, providing ideal breeding places for 
An. albimanus due to the species' preference for freshwater habitats with ample sunlight, algae and other organic matter. Other Anopheles species fed on a plantation's domesticated animals, providing the mosquito with abundant nutritional resources (McNeill 2010, 55-56).

Rice cultivation was especially important for creating new habitats for Anopheles species in the Americas. Rising rates of malaria on rice farms of the Caribbean, Suriname and Brazil implied a rising presence of Anopheles. There was a similar pattern in North America, where malaria and mosquitoes followed rice cultivation in South Carolina, Georgia and Louisiana. Before the establishment of large-scale commercial rice production in the 1680 s, South Carolina was relatively healthy compared to Caribbean colonies, where there was closer contact between Anopheles and people. As J.R. McNeill explains, the wetlands of coastal South Carolina "suited Anopheles' habits even before the installation of a rice economy, but the extensive irrigation of fields with shallow and stagnant water, full of organic debris, made good conditions much better." Four floodings each year provided especially favourable breeding grounds for An. quadrimaculatus. In South Carolina, plantations required the felling of trees and the construction of ponds and reservoirs, combined with ditches and canals for irrigation and drainage. These new habitats, in close proximity to enslaved African and Afro-American living quarters, provided female mosquitoes with a large supply of human blood and ample space to lay eggs (McNeill 2010, 205; McCandless 2011, 45, 126).

Similarly in Louisiana, subsistence rice production provided an abundance of ideal mosquito habitat. In 1718, the French Western Company ordered the purchase of enslaved Africans who could cultivate rice, along with barrels of rice seed from the African coast (Hall 1992; Dart 1931, 173). Rice farming grew substantially in the 1720 s, with the result that by the 1730 s, rice was the primary grain of local consumption. Ample evidence shows that it was consumed by European colonists, creoles, enslaved Africans, and African Americans (Hall 1992, 10, 122; Morris 2012, 48). In this period, rice was being cultivated with various methods in the lowlands of South Carolina, Georgia and Louisiana to produce still more Anopheles habitat (Gray 1933, 66). These regions became centres of endemic malaria in North America, demonstrating an association between rice cultivation and Anopheles growth, mirroring experiences in West Africa and Italy (McNeill 2010, 57; Boccolini et al., 2012). Meanwhile, growing plantation economies in North America also enabled expansion of Ae. aegypti, especially in Boston, Philadelphia and New York in summer, and Charleston, Norfolk and New Orleans year around.

\section{Urban environments}

Entomologists consider Ae. aegypti to be an "urban species" because it prefers feeding on human blood and breeding in artificial containers. The growth of the Atlantic trade system led to the establishment of numerous port cities that 
connected North America and Europe to ports across the tropical and subtropical Atlantic. Carrying pathogens, Ae. aegypti migrated across the Atlantic and around the world, multiplying into large populations wherever people transported it. Ae. aegypti, following the path of humans, migrated out of Africa, successfully colonizing most tropical and temperate coasts. By the late eighteenth and early nineteenth centuries, Atlantic ports were developing into large cities with high levels of traffic, dense residential development and diverse human communities with origins in Africa, Europe and the Americas.

Urban growth promoted environments favourable to Ae. aegypti through deforestation, urban construction, flooded landscapes and human immigration. Environmental alterations that removed forest cover and created new freshwater habitats provided a base for these mosquitoes. Their populations would then grow in concert with new canals and construction projects.

Outdoor and indoor urban spaces provided still more habitat for Ae. aegypti. Preferential breeding spaces of Ae. aegypti included any artificial container that could hold clean water, ranging from reservoirs, ponds and cisterns to gutters and drains. In coastal ports that depended on rainwater, cisterns promoted growth of mosquito populations. With the discovery in the early twentieth century of $A e$. Aegypti's role in transmitting yellow fever, public health authorities labelled this species the "cistern mosquito" (Boyce 1906, 11). Urban gardens also provided mosquitoes with breeding spaces. Inside homes, adult mosquitoes rested "in closets, cupboards, cabinets, behind doors, and even behind picture frames." Female mosquitoes would then feed at night in lighted rooms (Willoughby 2017, 16; Carpenter et al., 1955, 262).

Newcomers from the Old World (both free and enslaved) provided a large, diverse population of humans for Ae. aegypti to feed upon. Although this mosquito species can feed on other mammals, it has shown a preference for human blood over that of domesticated livestock. With Ae. aegypti carrying and transmitting yellow fever, the presence of this disease tracks the movement of the mosquito, from Havana to Port-au-Prince, from Charleston to Boston. By the end of the eighteenth century, colonial port cities up and down North America's Atlantic seaboard supported large populations of Ae. aegypti, which were becoming naturalized in their new urban habitat. One of the most memorable yellow fever epidemics in US history took place in Philadelphia in 1793, in the aftermath of the Haitian Revolution. The epidemic swept the young United States' first capital city, which became an important national centre of medical institutions.

By the nineteenth century in New Orleans, yellow fever's annual summer visit showed the extent to which Ae. aegypti had become established in the city. Here, mosquitoes bred in urban spaces along the waterfront, in residential areas, yards, gardens and cemeteries. Many of the city's unique architectural features, such as the ornamental above-ground cemeteries, proved to be especially attractive to this anthropophilic mosquito. Ongoing immigrant waves of non-immune peoples created ongoing conditions for epidemics: human blood provided mosquitoes with nutrition and city architecture provided them with 
habitat (Willoughby 2017). The construction of railroads connecting the ports to interior cities further increased the reach of Ae. aegypti. The spread of urban Ae. aegypti populations after the American Civil War led to the nation's worst yellow fever epidemic, which after breaking out in 1878 radiated up from New Orleans throughout the Mississippi Valley, causing pain and suffering as far north as Chicago and Pittsburgh (Willoughby 2017, 116).

\section{Conclusion}

Reviewing the history of how humans domesticated mosquitoes in North America would suggest that it may never be possible for humans to completely eliminate mosquitoes. People did not choose to domesticate these mosquitoes, and efforts to eliminate them over the long term have never been successful. Homo sapiens has inadvertently enlarged mosquito habitats, or else created habitats suitable for newly arriving mosquito species. In many cases, efforts to eradicate mosquitoes have revealed the role played by humans in attracting them. For example, in Panama in the early twentieth century, entomologists working to control malaria and yellow fever in the Canal Zone found that some Anopheles mosquitoes, including An. albimanus, preferred living and breeding in newly constructed landscapes. Human engineering projects attracted mosquitoes that preferred to live near human structures including workers' quarters, construction sites and railroads (Sutter 2007, 743-744). The rapid evolution of mosquitoes to pesticides further emphasizes the role that humans play in cultivating mosquitoes that are more resilient and genetically adapted to man-made chemical poisons.

Although the majority of mosquito species are content to live in the wild, a few species have shown strong preferences for human-modified environments, ranging from small agricultural settlements to large urban metropolises. The attraction of Anopheles and Aedes to humans and humanized environments would indicate that we may have no choice but to try to learn to live peacefully with mosquitoes. The fact that the settlement of North America involved the domestication of mosquitoes indicates that human societies will probably continue to attract mosquitoes simply by existing. Humans may in the end need to approach mosquito control cautiously and through a more thoughtful approach, while understanding the importance of built environments and wetlands to the life of these disease-carrying insects. As it becomes clear that powerful control measures like pesticides are not sustainable, changes in urban planning and rural land management may be the best way to diminish mosquito populations over time.

Humans and mosquitoes share a long history of coevolution and adaptation, and some mosquito species have learned to depend on Homo sapiens for survival. While humans could easily envision a happy future without these irritating and deadly pests, more and more mosquitoes have come to rely on humans for their sustenance and reproduction. As long as humans continue to transform wild and forest lands, it seems likely that humans will continue to be bothered 
by mosquitoes, with the ecological limits of mosquitoes expanding to merge with human communities. Mosquito numbers grew substantially in the second half of the twentieth century, ushered in by the ecological impacts of globalization, urban development, human population growth and climate change. The effects of climate change have already allowed Aedes and Anopheles mosquitoes to expand their range in North America, with Aedes becoming common in the western United States. If these trends continue, it is probable that humans and mosquitoes will be in even more frequent contact with each other across a widening geographical range.

\section{Bibliography}

Ackerknecht, Erwin H. 1945. Malaria in the Upper Mississippi Valley, 1760-1900. Supplements to the Bulletin of the History of Medicine 4. Baltimore: Johns Hopkins University Press.

Augustin, George. 1909. History of Yellow Fever. New Orleans: Searcy \& Pfaff Ltd.

Barber, M.A., W.H.W. Komp, and T.B. Hayne. 1927. The Susceptibility to Malaria Parasites and the Relation to the Transmission of Malaria of the Species of Anopheles Common in Southern United States. Public Health Reports (1896-1970) 42, no. 41: 2487-2502.

Boccolini, D. et al. 2012. Impact of Environmental Changes and Human-Related Factors on the Potential Malaria Vector, Anopheles Labranchiae (Diptera: Culicidae), in Maremma, Central Italy. Population and Community Ecology 49, no. 4: 833-842.

Boyce, Rubert. 1906. Yellow Fever Prophylaxis in New Orleans, 1905. London: Williams \& Norgate.

Boyce, Rubert. 1910. Health Progress and Administration in the West Indies. New York: E.P. Dutton and Company.

Carpenter, Stanley J., and Walter J. LaCasse. 1955. Mosquitoes of North America (North of Mexico). Berkeley: University of California Press.

Chambers, D.M., C.D. Steelman, and P.E. Schilling. 1981. The Effect of Cultural Practices on Mosquito Abundance and Distribution in the Louisiana Riceland Ecosystem. Mosquito News 41, no. 2: 233-240.

Chapin, Charles V. 1884. The Origin and Progress of the Malarial Fever Now Prevalent in New England. Providence: Kellogg Printing Co.

Christophers, S.R. 1960. Aedes Aegypti (L.) the Yellow Fever Mosquito: Its Life History, Bionomics and Structure. Cambridge: Cambridge University Press.

Dart, Henry P. 1931. The First Cargo of African Slaves for Louisiana, 1718. The Louisiana Historical Quarterly 14, no. 2: 163-181.

Foster, Woodbridge A. and Edward D. Walker. 2019. Mosquitoes. In Gary Mullen and Lance Durden eds. Medical and Veterinary Entomology, 3rd ed. London: Elsevier Academic Press, 261-326. https://doi.org/10.1016/B978-0-12-814043-7.00015-7

Gates, Bill. 2016. Mapping the end of Malaria. In GatesNotes on 10 Oct at https://www .gatesnotes.com/Health/Mapping-the-End-of-Malaria on 09.10.2020.

Goodyear, James D. 1978. The Sugar Connection: A New Perspective on the History of Yellow Fever. Bulletin of the History of Medicine 52: 5-21.

Gordon, David M., and Shepard Krech III, eds. 2012. Indigenous Knowledge and the Environment in Africa and North America. Oxford: Ohio University Press. 
Gray, Lewis Cecil. 1933. History of Agriculture in the Southern United States to 1860, Vol. I. Washington: The Carnegie institution of Washington.

Hall, Gwendolyn Midlo. 1992. Africans in Colonial Louisiana: The Development of AfroCreole Culture in the Eighteenth Century. Baton Rouge: Louisiana State University Press.

Hilliard, Sam B. 1979. Site Characteristics and Spatial Stability of the Louisiana Sugarcane Industry. Agricultural History 53, no. 1: 254-69.

Hirsch, August. 1883. Handbook of Geographical and Historical Pathology, Vol. I, translated by Charles Creighton. London: The New Sydenham Society.

Howard, Leland O., Harrison G. Dyar, and Frederick Knab. 1912. The Mosquitoes of North and Central America and the West Indies. Washington, DC: Carnegie Institute.

Humphreys, Margaret. 2001. Malaria: Poverty, Race, and Public Health in the United States. Baltimore: The Johns Hopkins University Press.

Kelton, Paul. 2007. Epidemics and Enslavement: Biological Catastrophe in the Native Southeast, 1492-1715. Lincoln: University of Nebraska Press.

Kiszewski, Anthony et al. 2004. A Global Index Representing the Stability of Malaria Transmission. American Journal of Tropical Medicine and Hygiene 70, no. 5: 486-498.

Lee, Chan. 1960. A Culture History of Rice With Special Reference to Louisiana. Ph.D. Thesis, Louisiana State University.

Lounibos, L. Philip. 2002. Invasions by Insect Vectors of Human Disease. Annual Review of Entomology 47: 233-266.

McCandless, Peter. 2011. Slavery, Disease, and Suffering in the Southern Lowcountry. Cambridge: Cambridge University Press.

McCann, James C. 2005. Maize and Grace: Africa's Encounter with a New World Crop. Cambrdige: Harvard University Press.

McNeill, J.R. 2007. Yellow Jack and Geopolitics: Environment, Epidemics, and the Struggles for Empire in the American Tropics, 1640-1830. In J.R. McNeill Alf Hornborg, and Joan Martinez-Alier eds. Rethinking Environmental History: WorldSystem History and Global Environmental Change. Lanham: AltaMira Press: 199-220.

McNeill, J.R. 2010. Mosquito Empires: Ecology and War in the Greater Caribbean, 16201914. Cambridge: Cambridge University Press.

Moore, Jason W. 2000. Sugar and the Expansion of the Early Modern World-Economy: Commodity Frontiers, Ecological Transformation, and Industrialization. Review: A Journal of the Fernand Braudel Center 23, no. 3: pp. 409-433.

Morris, Christopher. 2012. The Big Muddy: An Environmental History of the Mississippi and Its Peoples from Hernando de Soto to Hurricane Katrina. Oxford: Oxford University Press.

Mullen, Gary and Larry Durden eds. 2002. Medical and Veterinary Entomology, 1st ed. Elsevier Academic Press.

Nash, Linda. 2006. Inescapable Ecologies: A History of Environment, Disease, and Knowledge. Berkeley: University of California Press.

Patterson, K. David. 1992. Yellow Fever Epidemics and Mortality in the United States, 1693-1905. Social Science and Medicine 34, no. 8: 855-865.

Powell, Jeffrey R., and Walter J. Tabachnick. 2013. History of Domestication and Spread of Aedes Aegypti - A Review. Memórias do Instituto Oswaldo Cruz 108, no. Suppl. I: $11-17$.

Ries, Maurice. 1962. The Mississippi Fort, Called Fort de la Boulaye. Louisiana Historical Quarterly 19, no. 4: 1-73.

Singer, Charles, and E. Ashworth Underwood. 1962. A Short History of Medicine, 2nd ed. Oxford: At the Clarendon Press. 


\section{Urmi Engineer Willoughby}

Sinka, Marianne E. et al. 2010. The Dominant Anopheles Vectors of Human Malaria in the Americas: Occurrence Data, Distribution Maps, and Bionomic Précis. Parasites \& Vectors 3, no. 72: 1-26.

Sutter, Paul S. 2007. Nature's Agents or Agents of Empire? Entomological Workers and Environmental Change during the Construction of the Panama Canal. Isis 98, no. 4: 724-753.

Thwaites, Reuben Gold ed. 1900. The Jesuit Relations And Allied Documents: Travels And Explorations of the Jesuit Missionaries In New France, 1610-1791, Vol LXVII, Lower Canada, Abenakis, Louisiana, 1716-1727. Cleveland: Burrows.

Usner, Daniel H. 1992. Indians, Settlers, E Slaves in a Frontier Exchange Economy. Chapel Hill: University of North Carolina Press.

Valenčius, Conevery Bolton. 2002. The Health of the Country: How Americans Understood Themselves and Their Land. New York: Basic Books.

Watts, David. 1987. The West Indies: Patterns of Development, Culture, and Environmental Change Since 1492. Cambridge: Cambridge University Press.

Webb, James L.A. 2009. Humanity's Burden: A Global History of Malaria. Cambridge: Cambridge University Press.

Webb, James L.A. 2014. The Long Struggle against Malaria in Tropical Africa. Cambridge: Cambridge University Press.

Willoughby, Urmi Engineer. 2017. Yellow Fever, Race, and Ecology in Nineteenth-Century New Orleans. Baton Rouge: Louisiana State University Press. 